\title{
Performance of Slurry Infiltrated Fibrous Concrete - A Comprehensive Review
}

\author{
J. Renuka ${ }^{1, *}$ and K. Rajasekhar ${ }^{2}$ \\ ${ }^{1}$ Department of Civil Engineering, G.V.P.College for Degree and P.G.Courses (A), Visakhapatnam, Andhra Pradesh, India \\ ${ }^{2}$ Department of Civil Engineering, A.U. College of Engineering (A), Andhra University, Visakhapatnam, Andhra Pradesh, India
}

Received 15 March 2021; Accepted 6 August 2021

\begin{abstract}
Though construction industry may be little slow at adopting new technologies, it is the time to develop high performance cutting edge building materials to address various complex and diverse engineering needs in terms of high strength, more durability, ability to sustain under dynamic loads due to natural disasters, fire accidents, chemical attacks and terrorist blasts etc. The one of the high performance materials is the slurry infiltrated fibrous concrete (SIFCON), which has larger energy absorption capability along with good mechanical characteristics. In order to improve the performance of SIFCON, research studies have been made in progressing manner in the past decade. Most of the studies were focused on study of strength and durability of SIFCON against the change of fibre material, geometry, shape and its volume fraction. A limited number of research studies were dedicated to investigate the serviceability aspects of SIFCON with a view to maintain long term sustainability. There is a few research finding on performance of SIFCON under thermal environment. The outcome of the investigations in the form of publications in reputed Scopus indexed journals is limited, but notable research contributions have been reported. In this paper an attempt has been made to review the research findings in terms of improving the performance of SIFCON under different considerations. The review provides a significant information on SIFCON which may guide the researchers and practitioners in the relevant field.
\end{abstract}

Keywords: SIFCON, Steel Fibre, Strength, Durability, Serviceability

\section{Introduction}

Concrete is a quasi-brittle cementitious material composed of cement, sand, crushed stone or gravel (aggregate), chemical admixtures and water. Concrete is widely used as construction material in the world with an annual production of over ten billion tones. It is expected to grow the demand of concrete is approximately 18 billion tons a year by 2050 Shafigh et al., (2014) [1]. One survey explored that concrete is the most consumed material next to water in the world by mass and stated that about three tonnes per year used for every person on earth Gagg, 2014; Monteiro et al., (2017) [2-3]. Though the use of concrete is essential but the occurrence of cracks in concrete structures is unavoidable. Concrete is usually suffers from cracking due to various reasons such as mechanical loading, some deleterious reactions and environment loading. The source for crack in concrete structure is primarily due to tensile stresses caused by mechanical loading. When the induced tensile stress exceeds the tensile strength of the material, the cracks occur and the width of the crack reaches beyond a critical value such that the durability, serviceability and appearance of the structure are impaired. Therefore, the plain concrete does not withstand easily tensile and shear stresses and due to which, it is unsuitable for most of the structural applications. To overcome the drawback of lower tensile strength and brittle character of the plain concrete, reinforced cement concrete was developed through embedding steel in the form of rods, bars or meshes at the tensile zone of the concrete in the $19^{\text {th }}$ century with a view to improve tensile strength suitable to the needs of structural

*E-mail address: prenuka7@gmail.com

ISSN: 1791-2377 @ 2021 School of Science, IHU. All rights reserved. doi:10.25103/jestr.145.19 applications. The reinforced cement concrete has been used as versatile construction material as it is strong in compression as well as in tension. RCC also providing resistance to deterioration and environmental effects to which it is exposed.

Moreover, around four decades, efforts were made to develop high performance concrete to meet certain characteristics suitable to specific application and environment. The efforts led not only to increase its strength, but also to improve its durability, resistance to various external agents, high rate of hardening, etc., Brandt, (2008) [4]. Specifically to overcome the inherent brittleness of the concrete, a number of studies were carried out to develop fibre-reinforced cement composites. Fibre-reinforced concrete (FRC) attracted the concrete community gradually as it allows reduced construction time and labor costs. The externally bonded steel plate with carbon fibre reinforced polymer (CFRP) laminate is commonly employed in construction industry for the purpose of shear strengthening of reinforced concrete beams. But CFRP laminate is expensive and may lead to corrosion of steel plate if exposed to atmosphere. Alam and Riyami (2018) [5] made an attempt to develop high strength natural fibre based composites to overcome these drawbacks. The experimental study has been concluded that beams strengthened with natural fibre composite plates had shown higher ductility and higher failure loads as compared to those of CFRP laminates. Because of widely availability of natural fibres and offer certain benefits over traditional reinforcement materials in terms of low cost, lower density, non-toxicity, recyclability and biodegradability etc., several attempts have been made to use variety of natural fibres i.e., certain animal fibres and 
plant cellulose fibres for developing different fibre reinforced concrete materials. However, the high rate absorption of moisture due to high hydroxyl content of cellulose, poor interfacial adhesion between the natural fibres and resin causes poor mechanical properties. After thorough review of recent articles related to FRC, Yoo et al., (2019) [6] presented a comprehensive overview of mechanical properties and structural implications of FRC through covering various aspects related to material behaviour, strengthening performance, structural implications under different loading conditions such as static, impact, blast, fire, fatigue, etc. One of their significant conclusions revealed that steel fibres proved to be high efficiency and led to ductile behavior of compressed high strength concrete elements along with the desired effect at long-term loading.

As there is a need of addressing various challenges posed by the modern structural requirements, focus of research diverted towards investigating materials possessing improved properties such as strength, stiffness, impact and durability. Though FRC's with different varieties of fibres has been used for many structural applications, the ductility of FRC's has to be improved considerably. The ductility of FRC's depends on type of fibre, aspect ratio and strength of fibre and volume fraction of fibres used in preparing the specimen. The attempts have been made to improve ductility of FRC's using fibres upto $6 \%$, but there is a difficulty in placing and mixing of high volume of fibres. To obviate these difficulties and to meet the modern structural requirements, another high performance and high strength material called slurry infiltrated fibrous concrete (SIFCON) was developed.

Originally, Haynes proposed the technique of infiltrated layers of steel fibres with Portland cement in 1968. This technique was modified in the year 1979 by Lankard and he developed SIFCON through incorporating large amounts of steel fiber in moulds to form very dense network of fibers. Rattan, A., \& Singh, J. (2018) [7]. The SIFCON may allow $40-200 \mathrm{~mm}$ long and 5 to $20 \%$ of volume fibrous fraction. Brandt, (2008); Sampath and Asha, (2020) [4][8] and matrix is made of flowing cement mortar slurry. The matrix contains no coarse aggregates, but a high amount of cementitious substance. However, some amount of fine or coarse sand and certain additives like fly ash, metakaolin, micro silica etc. The casting procedure for preparing SIFCON is also different that of FRC's. It is usually fabricated by infiltrating a bed of preplaced fibres with cement slurry. SIFCON possesses superior mechanical properties such as compressive strength, tensile strength, shear strength, flexural strength and extraordinary toughness. It has been extremely attracted for construction of high rise buildings, mega structures and off shore structures etc., due to its special characteristics such as crack arresting, durability and seismic resistance. Because of high strength and toughness, SIFCON has been employed especially for seismic resistant structures Yazici et al., (2010); Misir and Kahraman, (2013) [9-10].

\section{Comprehensive review of literature on SIFCON performance}

To address various challenges in the field of modern construction under rapid urbanization scenario and the need of developing high-rise buildings have been motivated to carryout various research attempts on improving the performance of SIFCON for the past decade. Some studies carried in recent times to predict the mechanical properties of SIFCON under various conditions with the help of algorithm based artificial neural networks also Reddy, (2017); Kumar and Rajasekhar,(2017)[11-12]. The ability to withstand a structure under sudden, unexpected impact loads is also an important issue to be addressed. SIFCON yields high impact resistance and excellent energy absorption characteristics when compared with ordinary reinforced concrete specimens Rao et al., (2010); Chun et al., (2013); Elavarasi and Mohan,(2018); Abhirami et al.,(2019); Azoom and paneem, (2017); Al-wahab Ali et al., (2020) [13-18]. The impressed performance of columns made of SIFCON with hybrid fibres in terms of load carrying capacity, energy absorption and ductility with varying the shape of fibre, cross-section and hollow ratio of column was reported in the literature Khamees et al.,(2020), Khamees et al., (2020)[18-19]. This paper is focused on review of various significant research findings during the period from 2010 to 2020 on the effects of various parameters on improving the performance and durability of SIFCON. An extensive search has been made to find SIFCON in titles, abstracts, key words of various articles reported in reputed journals during the decade shown in Table1.

Table 1. Summary of research attempts on characterization of SIFCON

\begin{tabular}{|c|c|c|c|c|c|c|}
\hline $\begin{array}{l}\text { Sl. } \\
\text { No }\end{array}$ & Author & Year & Type of fibre & Aspect ratio & $\begin{array}{l}\text { Volume } \\
\text { fraction }\end{array}$ & $\begin{array}{ll}\text { Type } & \text { of } \\
\text { admixture }\end{array}$ \\
\hline 1 & Yazıc1, et al., & 2010 & $\begin{array}{l}\text { Hooked-end steel } \\
\text { fibers }\end{array}$ & $\begin{array}{l}\text { Aspect ratio: } 40 \\
\text { (dia.0.75 } \mathrm{mm} \text { and } \\
\text { 30mm length) }\end{array}$ & $\begin{array}{l}25 \% \text { for oriented placement and } 16 \% \\
\text { for random placement }\end{array}$ & $\begin{array}{l}\text { Class C fly ash } \\
\text { and ground } \\
\text { granulated blast } \\
\text { furnace } \\
\text { (GGBS) }\end{array}$ \\
\hline 2 & Rao et al., & 2010 & Steel & $\begin{array}{l}\text { Aspect ratio: } 50 \\
\text { (dia. } 1 \mathrm{~mm} \text { and } 50 \mathrm{~mm} \\
\text { length) }\end{array}$ & $12 \%$ & ----- \\
\hline 3 & Wu et al.,[68] & 2010 & $\begin{array}{l}\text { Hooked-end steel } \\
\text { fibers }\end{array}$ & $\begin{array}{l}\text { Aspect ratio: } 60 \\
\text { (dia.0.5 } \mathrm{mm} \text { and } \\
\text { 30mm length) }\end{array}$ & $14.7-19.2 \%$ & ----- \\
\hline 4 & Farnam et al.,[69] & 2010 & Straight steel fibers & $\begin{array}{l}\text { Aspect ratio: } 120 \\
\text { (dia. } 0.25 \mathrm{~mm} \text { and } \\
\text { 30mm length) } \\
\text { Aspect ratio: } 60\end{array}$ & $\begin{array}{l}2 \%, 5 \% \\
10 \%\end{array}$ & Silica fume \\
\hline 5 & Abdollahi et al., & 2012 & Steel & $\begin{array}{lrl}(\text { dia. } 0.3 & \mathrm{mm} & \text { and } \\
30 \mathrm{~mm} & \text { length } & \text { and } \\
50 \mathrm{~mm}) & & \end{array}$ & $5 \%$ and $6 \%$ & ------ \\
\hline 6 & Tuyan\&Yazıcı.[70] & 2012 & $\begin{array}{l}\text { Hooked-end steel } \\
\text { fibers\& smooth fiber }\end{array}$ & $\begin{array}{l}\text { Aspect ratio: } 40-80 \\
\text { (dia.0.55-1.05 } \mathrm{mm} \\
\text { and } 30-60 \mathrm{~mm} \text { length) }\end{array}$ & & $\begin{array}{l}\text { Class C fly ash, } \\
\text { GGBS and silica } \\
\text { fume }\end{array}$ \\
\hline
\end{tabular}




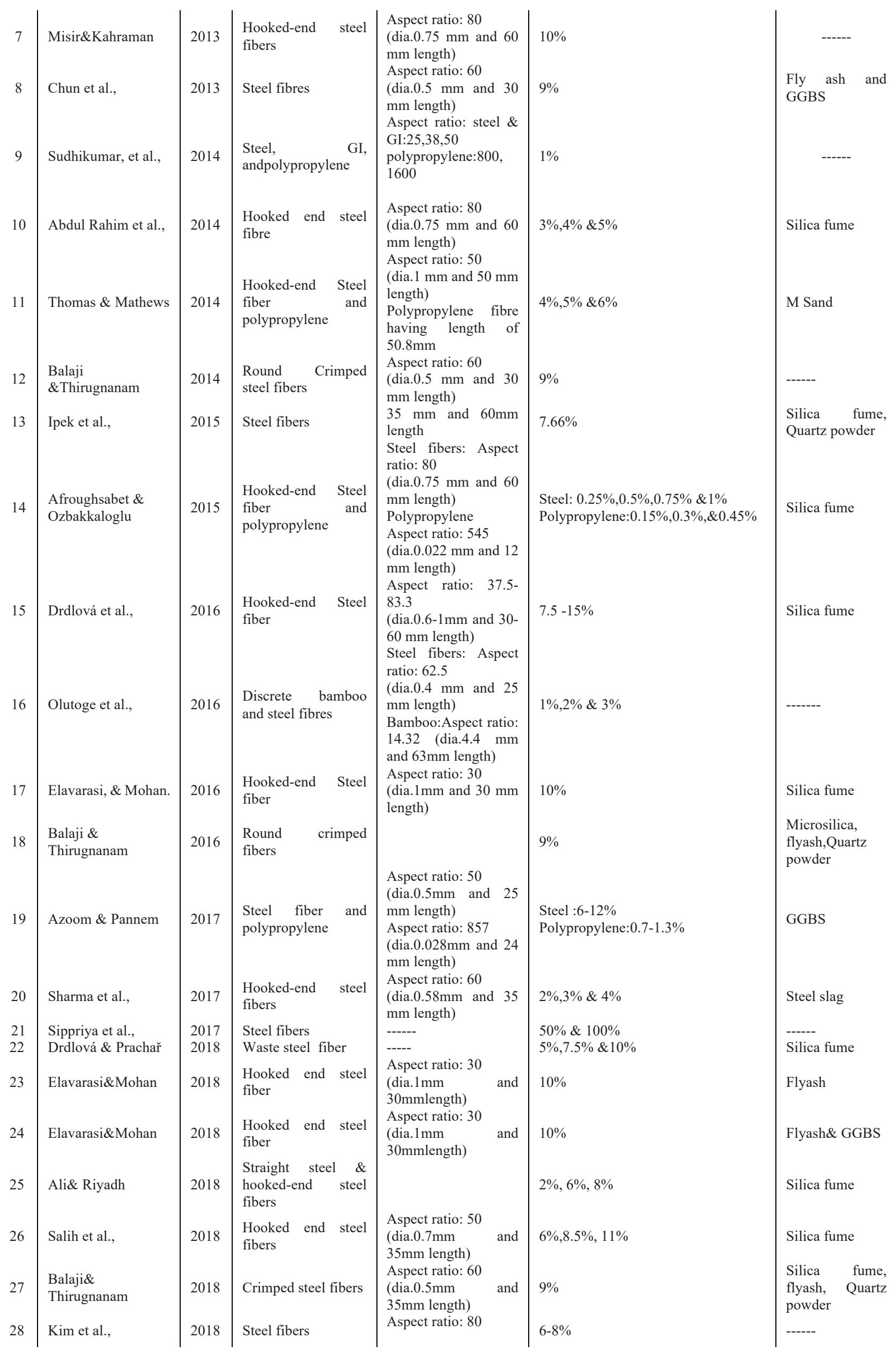




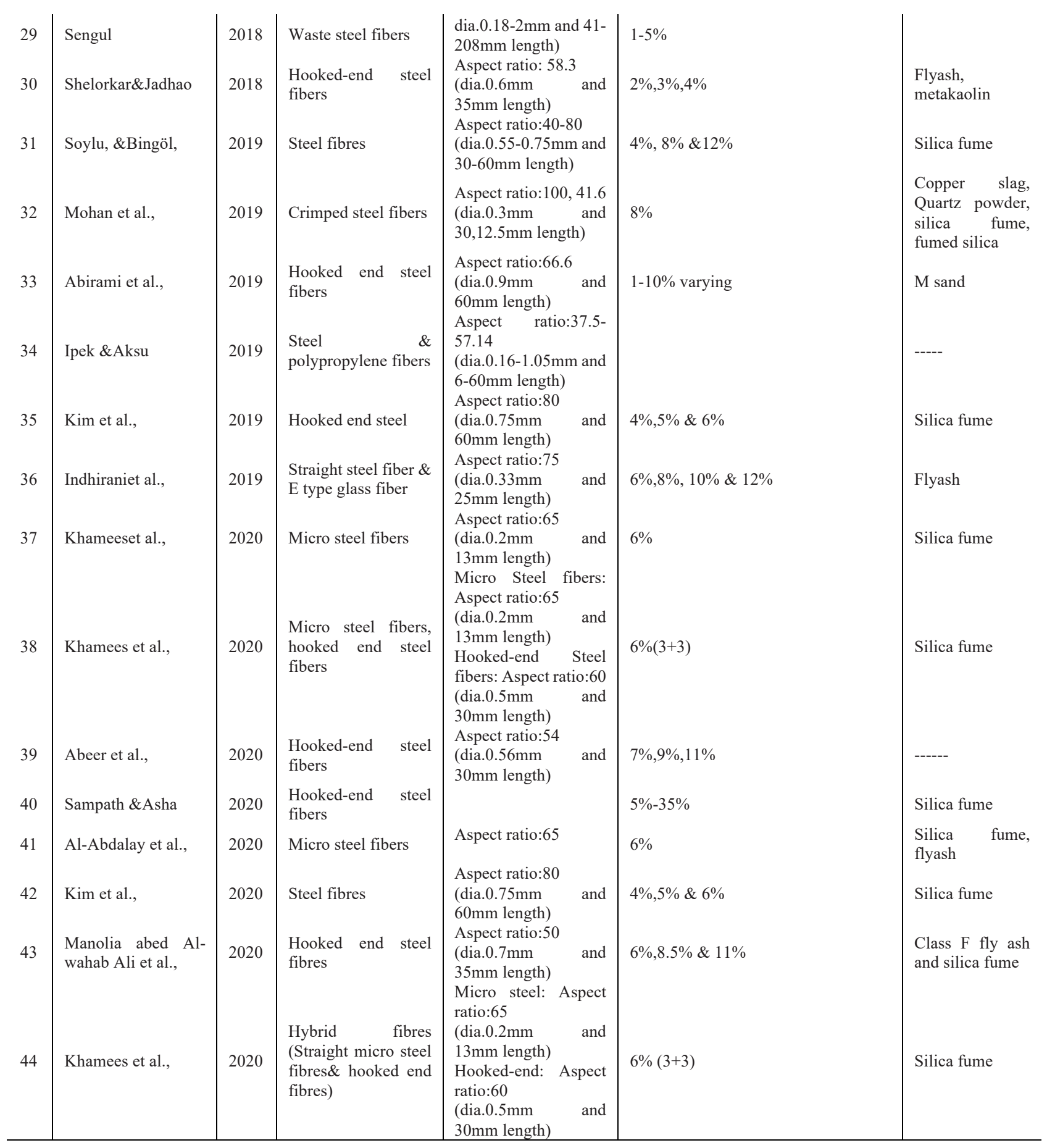

The review of the literature is organized into four aspects i.e., the effect of various fibres with different geometry on performance of SIFCON, durability issues of SIFCON under different environments, thermal characteristics and then suitability of SIFCON for improving the serviceability of structures. These aspects are discussed in the subsequent sections.

\subsection{Effect of various issues related to fibres on mechanical properties}

The mechanical characteristics of SIFCON are more influenced by the type of fibre, shape of the fibre, volume fraction, aspect ratio and orientation etc. Most of the works were confined to use of the fibres such as glass, polypropylene and steel. Earlier studies revealed that steel fibres are more preferable to improve the behaviour of concrete in terms of ductility, toughness, fatigue resistance, crack controlling, and energy absorption characteristics under different loading conditions Roesler et al.,(2006); Behfarnia and Behravan,(2014); Yin et al.,(2015); Faghih et al.,(2017); Mohajerani et al., (2019) [21-24] . The behaviour of SIFCON made with steel fibres in different forms namely straight, hooked end and crimped (non-straight) fibres as shown in Fig.1 with different aspect ratios were reported in the literature.

Most often, hooked end fibers and crimped fibres are used. Though attempts made on using straight fibers and deformed fibres, but they are not widespread. In the recent times focus also turned on to employ hybrid fibres i.e., the combination of hooked end and straight micro steel fibres Khamees et al., (2020) [25]. 


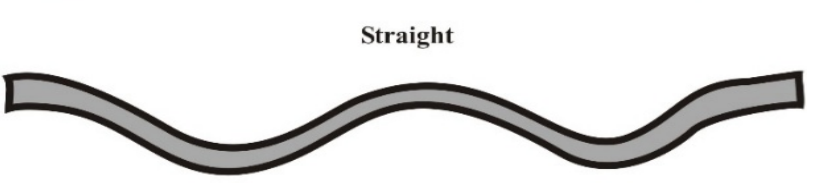

Crimped (Non-straight)

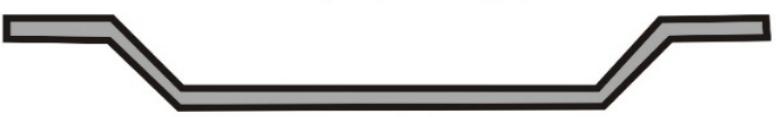

Hooked end

Fig. 1. Typical shapes of commonly used steel fibres in SIFCON

2.2 Compressive strength of SIFCON made with different size, shape and percentage volume fibrous fraction

Most of the researchers carried out their studies on investigation of compression strength of SIFCON made of steel fibres with different percentage of fibre volume fractions (4\%-15\%). The comparison of compressive strength of SIFCON with different percentages of volume fibre fraction as shown in Fig.2.

Thomas and Mathews (2014) [26] studied the strength of SIFCON made of various types of fibres with different percentage of volume fibre fractions. Studies revealed that compressive strength of SIFCON increases as the percentage of volume fibre fraction increases and observed that compressive strength is $39.8 \mathrm{MPa}$ at $5 \%$ volume fraction of hooked end steel fibres. Ozbakkaloglu and Afroughsabet (2015) [27] prepared SIFCON reinforced with steel fibres and polypropylene (PP) fibres separately as well as mixed in different proportions and studied mechanical characteristics. An enhancement in compressive strength is observed with the increase in fiber content of both PP and steel fibre fraction. The reason for this improvement is the ability of fibers to restrain the extension of cracks, reduction of stress concentration at the tip of cracks, and delay in growth rate of cracks.

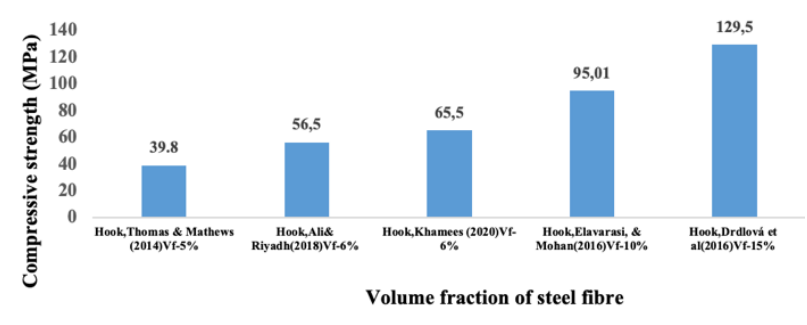

Fig. 2. Comparision of compressive strength of SIFCON made with different $\%$ of volume fibrous fraction

Elavarasi \& Mohan (2016) [28] made an attempt to determine the compressive strength of SIFCON with $10 \%$ of hook end steel fibres through a blend of silica fume. The effect of silica fume in different percentages ranging from 5\% to $25 \%$ with partial replacement of cement in SIFCON found that compressive strength is maximum $(95.01 \mathrm{MPa})$ at $15 \%$ of silica fume used. Drdlová et al., (2016) [29] prepared specimens of SIFCON with hook end steel fibres in different aspect ratios with four volume fractions (7.5-15\%). A significant energy absorption capacity was observed with specimens containing $15 \%$ volume fibre fraction and noticed that the specimens with $12.5 \%$ volume fibre fraction exhibits better compressive strength of $135.9 \mathrm{MPa}$. Ali and Riyadh (2018) [30] carried out laboratory tests on SIFCON made with two different mix proportions (1:1 and $1: 1.5)$ using $6 \%$ and $8 \%$ volume fractions of straight as well as hook end steel fibres. The study revealed that SIFCON with $8 \%$ volume fibre fraction, irrespective of shape shows maximum compressive strength. However, the specimens of SIFCON under 1: 1 mix shown maximum compressive strength when compared to SIFCON with 1:1.5 mix. Sengul (2018) [31] worked with waste steel fibres with different geometry in SIFCON production with a volume fraction of 0 to $5 \%$. From the experimental study, it was concluded that the compressive strength is increasing with the increase of fibre content of blended geometrical characteristics. Soylu and Bingöl (2019) [32] have conducted experimental study on the effect of steel fibers with aspect ratios of $40,55,65$, and 80 with volume fibre fraction in incremental steps of $0,4,8$ and $12 \%$ on compressive strength of SIFCON. Results concluded that the compressive strength of SIFCON is enhanced with the increasing fiber volume fraction upto $8 \%$. The compressive strength is observed to be increased with the increase of aspect ratio. However, this shows a significant aspect that the strength reduction occurs at $12 \%$ of fiber volume and they stated the reason for reduction is due to difficulty of placing mortar in between the fibres. Khamees et al., (2020) [25] carried out study on SIFCON with straight micro steel fibres, hook end and hybrid fibres separately for observing the compressive strength of SIFCON. From the results, concluded that though the compressive strength of SIFCON with $6 \%$ volume fraction is good but unfavorable effects such as spalling and more number of cracks were observed in the specimens made of hook end steel fibres. Further, disadvantages were obviated with the reinforcement of SIFCON with $6 \%$ of micro and hybrid fibres.

Moreover, in all these studies there is a remarkable improvement in compressive strength of SIFCON with the increase of percentage volume of fibre fraction. Increase in compressive strength of SIFCON to a great extent is observed with the use of micro steel fibres due to the random distribution of fibres in denser manner. Consequently, the distribution of fibres gives three dimensional reinforcement network and hence there may be the distribution of internal and external stresses in amicable way.

\subsection{Flexural strength of SIFCON with shape and percentage volume of fibre fraction}

Flexural strength is also one of the important required properties of concrete which is a measure of ability to withstand flexural loads. Some of works reported are closely focused on study of flexural behaviour of SIFCON reinforced with different fibres and geometry. Another important aspect is the fiber alignment in view of attaining superior performance of SIFCON in terms of flexural strength Yazici et al.,(2010) [9]. Fig.3 indicates the Comparison of flexural strength of SIFCON with percentage of volume fibre fraction.

Abdul Rahim et al., (2013) [33] investigated the flexural strength of SIFCON under different curing conditions and emphasized that specimens cured in water shown good flexural strength than the specimens cured under steam at 80 ${ }^{\circ} \mathrm{C}$. In addition to that, maximum amount of flexural strength was obtained when $5 \%$ volume of fibre fraction was added. Sudhikumar, et al., (2014) [34] prepared SIFCON with 1\% of steel fibre, galvanized iron fibre and PP fibres as reinforcement materials in different aspect ratios. Results show that the flexural strength decreases with the increase of aspect ratio. This indicates that at lower aspect ratios the energy absorption resistance of the SIFCON also increases. Ipek et al., (2015) [35] prepared novel SIFCON which is a 
mixture of reactive powder concrete and SIFCON with a view to test its flexural strength under six different presetting pressure conditions ( 0 to $15 \mathrm{MPa})$. And concluded that maximum flexural strength $69.7 \mathrm{MPa}$ occurs at $15 \mathrm{MPa}$ presetting pressure condition and also maximum fracture toughness at presetting pressure of $12 \mathrm{MPa}$ was observed. Another study carried by Olutoge et al., (2016) [71] revealed that the increase of volume fraction of steel fibres give improvement in flexural strength whereas the increase of volume fraction of discrete bamboo fibres leads to decrease in flexural strength of SIFCON. Sharma et al., (2017) [36] prepared SIFCON specimens with partial replacement of fine aggregate with steel slag (10\% and $20 \%)$ with three different volume fractions $(2 \%, 3 \%$ and $4 \%)$ of steel fibres. Finally, $10 \%$ replacement of steel slag with fine aggregate gives favorable results when compared to $20 \%$ replacement. Incorporation of fibres in concrete gives more ductility when compared to normal concrete. Drdlova and prachar., (2018) [37] considered waste steel fibres as reinforcement fibre for preparing SIFCON. With the volume fractions of 5\%, 7.5\% and $10 \%$ of fibres shows an improvement in flexural strength of SIFCON and also observed more homogeneity of the matrix with low diameter fibres. SIFCON exhibits better blast resistance capacity and is more cost effective as waste steel fibres are used. Later, Ipek and Aksu (2019) [38] investigated the flexural behaviour of SIFCON reinforced with steel and PP fibres. As a result of the combination of these fibres gives more volume fraction and leading to increase in flexural strength as well as fracture toughness. This concluded that the PP fibre offers significant benefits in terms of lower density and cost as compared to that with steel fibres. Mohan et al., (2019) [39] investigated flexural behavior of SIFCON with steel crimped fibres of $8 \%$ volume fractions with two different lengths $(12 \mathrm{~mm}$ and $30 \mathrm{~mm})$. On the basis of their experimentation work, the flexural strength of $30 \mathrm{~mm}$ length fibre specimen performs better. Indhirani et al.,(2019) [40] cast SIFCON specimens reinforced with straight stainless steel and $\mathrm{E}$ type glass fibres with four volume fractions $(6 \%$ $12 \%)$ and a little amount of fly ash with constant amount (2\%) of glass fibres. An increase of $28.73 \%$ in flexural strength is obtained when compared to conventional concrete. Kim et al., (2020) [41] studied the flexural behavior and toughness of SIFCON with various volume fractions of steel fibres $(4 \%$ $6 \%$ ). The maximum flexural strength of $45 \mathrm{MPa}$ was obtained with the use of $6 \%$ volume fibre fraction. Investigations show an increase in fracture energy due to high bond between high performance slurry and steel fibres.

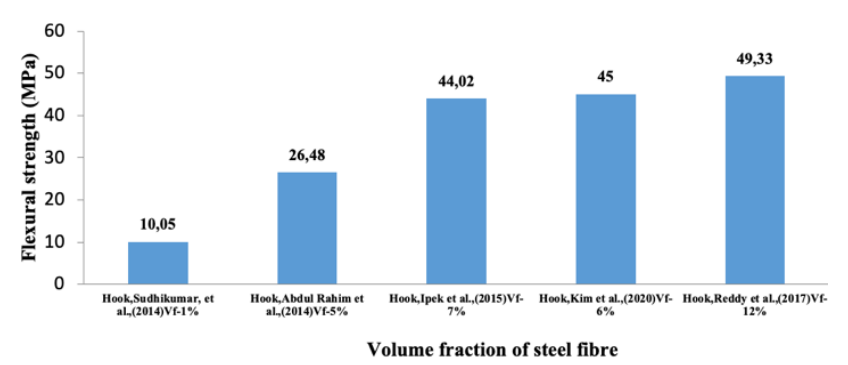

Fig. 3. Comparision of flexural strength of SIFCON with \% of volume fibrous fraction

The noticeable observation from the works is that there is a significant effect of fibre geometry on flexural strength of SIFCON. The flexural strength of SIFCON is gradually enhanced with the increase of fibre volume fraction. The homogeneous behaviour of composites and high performance of slurry are the cause for improvement in flexural strength of SIFCON.

\subsection{Split tensile strength of SIFCON with shape and percentage volume of fibre fraction}

Concrete structures are highly vulnerable to tensile cracking and hence it is essential to know the tensile behaviour of SIFCON. In almost all the studies researchers focused on investigating the split tensile strength of SIFCON reinforced with different percentages of fibre fraction. Fig.4 shows the Comparison of tensile strength of SIFCON with different percentages of volume fibre fraction.

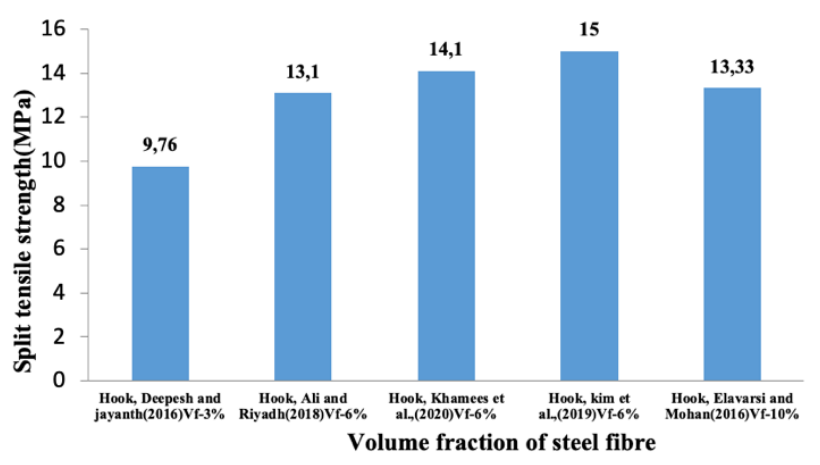

Fig. 4.Comparision of Split tensile strength of SIFCON with different \% of volume fibre fraction

Sippriya et al., (2017) [42] conducted test on SIFCON specimens and observed $75 \%$ increase in tensile strength of SIFCON when compared to conventional concrete of grade 20. Elvarasi et al., (2018) [43] carried out split tensile test on SIFCON specimens made with $6 \%, 8 \%$ and $10 \%$ volume fibre fraction. The tensile strength and fracture energy are observed to be increased with the increase of volume fraction of steel fibres. The fracture energy is observed to be maximum when $10 \%$ of volume fibre fraction used. This may be due to improvement of bond strength between fibres and matrix. Kim et al., (2019) [44] cast SIFCON specimens of different volume fractions $(4 \%, 5 \%$ and $6 \%)$ and tested the tensile strength of the specimens and concluded that tensile strength and energy absorption capacity are also increased with high volume fractions of fibres. But, the strain capacity decrease with increase of volume fractions of fibre content. Khamees et al., (2020) [25] tested three sets of SIFCON specimens reinforced with $10 \%$ of silica fume and $6 \%$ volume fraction of fibers (micro steel fibre, hook end steel fibre and mixing of steel fibres). The study concludes that the geometry of fibres effect the split tensile strength and toughness considerably due to network of fibres and their density. This indicates that the micro steel fibres imparts an improvement in split tension strength. Al-Abdalay et al., (2020)[45] made an attempt to prepare SIFCON with a partial replacement of cement with silica fume and fly ash using $6 \%$ micro steel fibre fraction. The same effect of micro steel fibres on split tensile strength is noticed. From the results, it may be attributed that the micro granulars of fly ash particles provide a bond between the fibre and matrix and as a result there is an improvement in mechanical properties of SIFCON is observed. When hooked end fibre employed to prepare SIFCON specimens made with micro steel fibres are used due to bond between the fibre and the matrix proposal with granular of flyash. Partial replacement of cement with silica fume $(10 \%$ and $15 \%)$ enhances split tensile strength increased to certain extent Salih et al.,(2018); Sampath and Asha ,(2020) [46][8]. 
It is observed that the split tensile strength of SIFCON increases with the increase of volume fraction of steel fibres. Especially while using micro steel fibres for reinforcement, the SIFCON exhibits more improvement in split tensile strength. The possible reason for this is the short and small size fibres have scope to occupy a greater number of fibres in unit area and it leads to denser network and thereby reducing the phenomenon of edge effect.

\section{Durability of SIFCON with different types of steel fibres}

Now a days, it is essential to ensure that any construction should possess durability to withstand sudden changes in climatic conditions, unforeseen chemical attacks and any kind of process of deterioration. If the study of durability aspects are ignored, the investment on the part of repairs is unavoidable. In this context, certain studies have been carried out by various researchers to assess the durability of SIFCON with different fibres under different conditions. Some of the researchers tried to develop SIFCON and study durability characteristics by employing hybrid fibres i.e., two or more fibres. Afroughsabet and Ozbakkaloglu (2015) [47] employed both hook end steel fibres $(0.25$ to $1 \%)$ and polypropylene fibres $(0.15$ to $0.45 \%)$ for making high strength concrete with the replacement of cement with $10 \%$ silica fume. The tests carried to know the electrical resistivity and water absorption revealed that the addition of silica fume improve the durability characteristics. There is a specific effect of type of fibre on durability of high strength concrete. The addition of polypropylene fiber increases the porosity and slight reduction in the electrical resistivity of concrete. But the addition of steel fibers decreases the electrical resistivity of concrete in a significant manner because of conductivity characteristics of the fibers. Armagan and Canbaz (2016) [48] prepared SIFCON specimens using steel and polypropylene fibres to study its behaviour through conducting ultrasonic pulse velocity (UPV) test under freezing and thawing environment in different cycles. The higher the freeze-thaw cycles the bending strength and compressive strength of the specimens were decreased. As far as the influences of type of fibre are concerned, the steel fibres have shown more positive benefits than polypropylene fibres. Shelorkar and Jadhao (2018) [49] focused on study of abrasion resistance and water sorptivity of SIFCON made with hook end steel fibres using fly ash and Metakaolin (MK) about $10 \%$ by weight of cement. The content of Fly ash and MK is attributed to enhance abrasion resistance of SIFCON. However, higher replacement levels of these materials ( $15 \%$ of MK) are not advisable in improving the core durability of SIFCON. An increase in compressive strength is observed with the decrease in sorptivity. Further, the depth of wear decreases with the increase in compressive strength. The partial substitution of fly ash (10 to $30 \%)$ in the place of cement with $10 \%$ steel fibres in SIFCON gives better durability characteristics due to reduction in deterioration and sorption coefficient because the fly ash causes improvement of matrix bond Elavarasi and Mohan,(2018);Alrubaie et al., (2019, 2019a) [50-52] made an attempt to study the effect of acid on strengths of SIFCON made with varying amounts of steel fibres (1.5 to 10\%) and MK. The compressive strength of SIFCON is observed to be increased when specimens are placed in diluted nitric acid for a period of 180 days. The SIFCON mix with MK shown lower resistance to corrosion and at the same time MK reduces the permeability of SIFCON. Epoxy protective coatings and corrosion inhibiter admixture improves the efficiency of SIFCON under corrosive environment. The effect of alignment of steel fibres on corrosion resistance is not significant. Shelorkar and Jadhao (2019) [53] conducted a study on SIFCON with use of hooked end steel fibres ( 0 to $4 \%$ volume fractions) and the partial replacement of fine sand with steel slag (0 to 20\%). Reduction in Compressive strength was observed when the SIFCON specimens are exposed to sulphate solution as well as $3 \%$ sulphuric acid. The performance of SIFCON with steel slag under chemical attack is good as compared to that with normal concrete. The durability studies on SIFCON were disclosed that the mono fibre SIFCON composite exhibits better performance in terms of durability over a limited range.

\section{Thermal characteristics of SIFCON reinforced with different fibres}

Concrete structures offer resistance to temperature upto a certain extent. Over a period of exposure to high temperatures the concrete structural elements undergo detoriation and change its color. Therefore, it is necessary to evaluate the performance of SIFCON exposed to different range of temperatures in different periods. A few studies have been reported in the literature to know thermal behaviour of SIFCON at different temperatures. Shelorkar and Jadhao (2019) [55] made an investigation on residual strength of SIFCON reinforced with steel fibres with partial replacement of cement by fly ash and $\mathrm{MK}$ at elevated temperatures $200^{\circ} \mathrm{C}$ $-400{ }^{\circ} \mathrm{C}$. SIFCON reinforced with steel fibres exhibits good compressive strength up to $400{ }^{\circ} \mathrm{C}$ and losses its strength when temperature increases beyond $400{ }^{\circ} \mathrm{C}$. Beglarigale et al., (2016) [54] studied flexural strength of SIFCON at different temperatures in the range of $300-900{ }^{\circ} \mathrm{C}$. The flexural performance of SIFCON is observed to be decreased at 600 ${ }^{\circ} \mathrm{C}$ due to decrease in cross-section of fibres and fibre-matrix bond strength because of the oxidation of external surface of steel fibers and also destruction of C-S-H structure at high temperatures. Flexural strength of SIFCON shows significantly less reduction at higher temperatures as compared to other mechanical properties such as compressive strength, flexural strength and elastic modulus of SIFCON. The compressive strength and elastic modulus of SIFCON are reduced drastically with the rise of temperature. The properties of SIFCON are decreased considerably when the temperature increased beyond $600{ }^{\circ} \mathrm{C}$ due to decomposition of C-S-H and $\mathrm{CH}$ hydrates Abbas and Kadhum, (2020); Hashim and Kadhum, (2020); Kim et al., (2020) [5658] made a novel study to analyze flexural and compressive strength of steel fiber reinforced cement composites with percentage of polymer subjected to a high temperatures for a period of 1 hour. The compressive strength of SIFCON was higher at $0.5 \%$ polymer after exposed to high temperature environment. However, no significant difference was observed in flexural strength of SIFCON irrespective of percentage of polymer content. The primary reason for this outcome is the formation of capillary pores due to melting and burning of polymer at high temperatures.

The behaviour of SIFCON subjected to fire is more interesting. The interlocking action of the fibres attribute better performance of SIFCON at higher temperatures and the crack growth has been inhibited due to controlled crack propagation. The moderate increment of weight takes place due to inclusion of steel fibres and consequently the increase in the elastic modulus and the high content of steel fibres 
offers resistance to spalling and cracking at high temperatures.

\section{Serviceability of SIFCON reinforced with different fibres}

The protection of infrastructure from any kind of deterioration over the life cycle of the structure is necessary. Deterioration is inevitable for any reinforced concrete infrastructure like bridges, buildings, pavements etc. Therefore it is essential to consider strength and serviceability as primary objectives of any structural design. To enhance the serviceability of the existing defected concrete structures it is required a suitable material for retrofitting. The SICON has no exception to use as retrofitting material for repairing or upgrading of concrete structures.

To this end very few research attempts have been made to identify the suitability of SIFCON as external shear reinforcement for eliminating the brittle failure of existing structures. Hameed et al.,(2019);Hameed et al., (2020); Hameed et al., (2020a) [59-61] made an attempt to study the use of epoxy bonded SIFCON layers to improve the service life of structural members. The flexural strength, toughness and ductility of the composite sections are improved considerably with the increase of percentage of steel fibre fraction and layer thickness. The enclosing SIFCON jackets and the conventional glass fibre reinforced concrete (GFRP) sheets for strengthening of concrete specimens are usually employed. Fibre length and jacket thickness are primary factors in SIFCON jacketing case whereas number of layers and ply configuration are the influencing factors for strengthening the existing structures. It is reported that both SIFCON and GFRP confinement methods enhance strength, strain and energy absorption capacity of concrete cylinders Abdollahi et al., (2012) [62]. The SIFCON is also employed for flat slabs to enhance the serviceability characteristics. Helal et al.,(2020) [63] made an attempt to use 30mm thick layer SIFCON for repairing five damaged slabs in compression zone and other five slabs damaged in tension zone. After testing it was confirmed that there is a remarkable improvement in flexural strength, deflection characteristics and ductility of the specimens. $2-39 \%$ flexural strength is improved in compression zone and $4-71 \%$ in tension zone is observed in SIFCON slab specimens when compared to control slab specimens.

The structures which are constructed in seismic-prone areas are need to be strengthened with the aid of economic and reliable strengthening techniques. In this context Misir and Kahraman (2013),[64] proposed a noval seismic strengthening technique for non-seismically detailed beam column joints. Pre-fabricated SIFCON composite corner and plate blocks on joints with anchorage rods were proposed and tested under quasi static loading. The strengthen specimens shows improved stiffness, ductility, energy dissipation and lateral strength considerably when compared to control specimens. Balaji and Thirugnanam (2014, 2016, and 2018) [65-67] carried out rigorous studies on strengthening of beam column joints. $20 \mathrm{~mm}$ thick precast SIFCON laminates were used to strengthen the reinforced concrete and fiber reinforced concrete beam column joints and tested the specimens under cyclic loading with a view to observe the load deformation behaviour, ductility parameters , ultimate load carrying capacity and failure characteristics. The experimentation results have motivated to employ SIFCON for strengthening beam column joints as it gives enormous improvement in those parameters.

\section{Conclusions}

The attention of researchers in the field of concrete technology has been turned to carry investigations on studying the behaviour of SIFCON under different loading conditions, thermal environment so as to check the suitability for strengthening the existing reinforced concrete structures. It is evident from the review of literature that the addition of SIFCON in conventional concrete minimizes crack propagation, enhances load carrying capacity, improves ductility characteristics, increases strength as well as energy absorption capability (toughness). Because of more difficulty is involved in placing the fibres in moulds, most of the studies were confined to use 1 to $12 \%$ of fibres only. The geometry and volume fraction of fibres are also the most influencing factors on the performance of SIFCON. The strength of SIFCON reduces considerably when exposed to high temperatures. Instead of using single type of fibres, the use of hybrid fibres in SIFCON provides favorable results in specific applications. Further, studies may be carried on characterization of SIFCON reinforced with hybrid fibres under high temperature environment. SIFCON may be employed as retrofitting material depending on the specific conditions to meet unanticipated climatic situations. SIFCON may help to improve the serviceability of the existing structures under deterioration. It is observed from the review of the literature that certain research gaps were identified. Though few investigations made to understand the characterization of SIFCON under seismic loads, but those are minimal. The economic factor has also not been considered properly in comparison to conventional concrete. It may be further scope to carry investigations on SIFCON with the inclusion of novel admixtures, economical fibres under dynamic loading patterns. The review may stimulate the academicians as well as practitioners in the field of construction engineering.

This is an Open Access article distributed under the terms of the Creative Commons Attribution License.

\section{References}

1. Shafigh, P., Mahmud, H. B., Jumaat, M. Z., \& Zargar, M. Agricultural wastes as aggregate in concrete mixtures-A review. Construction and Building Materials, 53, 110-117 (2014).

2. Gagg, C. R. Cement and concrete as an engineering material: An historic appraisal and case study analysis. Engineering Failure Analysis, 40, 114-140 (2014).

3. Monteiro, P. J., Miller, S. A., \& Horvath, A.Towards sustainable concrete. Nature materials, 16(7), 698-699 (2017).
4. Brandt, A. M. Fibre reinforced cement-based (FRC) composites after over 40 years of development in building and civil engineering. Composite structures, 86(1-3), 3-9 (2008).

5. Alam, M. A., \& Al Riyami, K. Shear strengthening of reinforced concrete beam using natural fibre reinforced polymer laminates. Construction and Building Materials, 162, 683-696 (2018). 
6. Yoo, D. Y., Banthia, N., Fujikake, K., Kim, Y. H., \& Gupta, R. Fiber-Reinforced Cement Composites: Mechanical Properties and Structural Implications 2019. Advances in Materials Science and Engineering, (2019).

7. Rattan, A., \& Singh, J. Development of Ultra High Strength SIFCON. In International Conference on Sustainable Waste Management through Design (pp. 178-186). Springer, Cham(2018).

8. Sampath, P., \& Asha, P. Mechanical properties of slurry infilterated fibrous concrete (Material) with hooked end fibre. Materials Today: Proceedings (2020).

9. Yazici H, Aydin S, Yigiter H, Yardimci M Y and Alptuna G, Improvement on SIFCON performance by fiber orientation and high-volume mineral admixtures. J. Mater. Civil Eng. 22(11): 1093-110 (2020).

10. Misir, I. S., \& Kahraman, S. Strengthening of non-seismically detailed reinforced concrete beam-column joints using SIFCON blocks. Sadhana, 38(1), 69-88(2013).

11. Reddy, T. Chandra Sekhara. "Predicting the strength properties of slurry infiltrated fibrous concrete using artificial neural network." Frontiers of Structural and Civil Engineering 490-503 (2018).

12. Kumar, G. S., \& Rajasekhar, K. Performance analysis of Levenberg-Marquardt and Steepest Descent algorithms based ANN to predict compressive strength of SIFCON using manufactured sand. Engineering science and technology, an international journal, 20(4), 1396-1405(2017).

13. Rao, H. S., Ghorpade, V. G., Ramana, N. V., \&Gnaneswar, K. Response of SIFCON two-way slabs under impact loading. International Journal of Impact Engineering, 37(4), 452458 (2010).

14. Chun, Pang-jo, et al. "Experimental study on blast resistance of SIFCON." Journal of Advanced Concrete Technology 144-150 (2013).

15. Elavarasi, D., and K. Saravana Raja Mohan. "On low-velocity impact response of SIFCON slabs under drop hammer impact loading." Construction and Building Materials 160, 127-135 (2018).

16. Abirami, T., et al. "Experimental research on impact response of novel steel fibrous concretes under falling mass impact." Construction and Building Materials 222, 447-457(2019).

17. Azoom, K. T., and Rama Mohan Rao Pannem. "Punching strength and impact resistance study of sifcon with different fibres." (2017).

18. Al-wahab Ali, et al. "Study the behavior of slurry infilterated fibrous concrete (SIFCON) under impact loading." IOP Conference series: Materials Science and Engineering 737 (2020).

19. Khamees, Shahad S., Mohammed M. Kadhum, and Nameer A. Alwash. "Effect of hollow ratio and cross-section shape on the behavior of hollow SIFCON columns." Journal of King Saud University-Engineering Sciences (2020).

20. Khamees, Shahad S., Mohammed M. Kadhum, and Nameer A. Alwash. "Experimental and numerical investigation on the axial behavior of solid and hollow SIFCON columns." SN Applied Sciences, 1-15 (2020).

21. Roesler, J.R.; Altoubat, S.A.; Lange, D.A.; Rieder, K.A.; Ulreich, G.R. Effect of synthetic fibers on structural behavior of concrete slabs-on-ground. Materials Journalpg. 3-10 (2006).

22. Behfarnia, K.; Behravan, A. Application of high performance polypropylene fibers in concrete lining of water tunnels. Materials and Design. 55, 274-279, (2014).

23. Yin, S.; Tuladhar, R.; Shi, F.; Combe, M.; Collister, T.; Sivakugan, N. Use of macro plastic fibres in concrete: A review. Construction and Building Materials. 93, 180-188(2015).

24. Mohajerani, A., Hui, S. Q., Mirzababaei, M., Arulrajah, A., Horpibulsuk, S., Abdul Kadir, A., \& Maghool, F. Amazing Types, Properties, and Applications of Fibres in Construction Materials. Materials, 12(16), 2513(2019).

25. Khamees, S. S., Kadhum, M. M., \& Nameer, A. A.. Effects of Steel Fibers Geometry on the Mechanical Properties of SIFCON Concrete. Civil Engineering Journal, 6(1), 21-33(2020).

26. Thomas, Arun Aniyan, and Jeena Mathews. "Strength and behaviour of SIFCON with different types of fibers." International Journal of Civil Engineering and Technology (IJCIET) 5.12 25-30, (2014).

27. Afroughsabet, Vahid, and Togay Ozbakkaloglu. "Mechanical and durability properties of high-strength concrete containing steel and polypropylene fibers." Construction and building materials 94 7382(2015).
28. Elavarasi, Mohan. "KSR, "Performance of Slurry Infiltrated Fibrous Concrete (Sifcon) with Silica Fume."." International Journal of Chemical Sciences 14.4 2710-2722(2016).

29. Drdlová, Martina, Radek Řídký, and René Čechmánek. "Influence of fibre type and fibre volume fraction on dynamic properties of slurry infiltrated fibre concrete." Materials science forum. Vol. 865. Trans Tech Publications Ltd, (2016).

30. Ali, Ahmed S., and Zolfikar Riyadh. "Experimental and Numerical Study on the Effects of Size and type of Steel Fibers on the (SIFCON) Concrete Specimens." International Journal of Applied Engineering Research 13.2 1344-1353(2018).

31. Sengul, Ozkan. "Mechanical properties of slurry infiltrated fiber concrete produced with waste steel fibers." Construction and Building Materials 186: 1082-1091(2018).

32. Soylu, Nurullah, and Ahmet Ferhat Bingöl. "Research on effect of the quantity and aspect ratio of steel fibers on compressive and flexural strength of SIFCON." CHALLENGE 5.1: 29-34 (2019).

33. Abdul Rahim, Mustaqqim \& Aziz, Farah \& Md Ghazaly, Zuhayr \& Shahidan, Shahiron \& Mohamad Ibrahim, Norlia. Flexural Behaviour Of High Performance Slurry Infiltrated Fiber Reinforced Concrete With Different Curing Method. Australian Journal of Basic and Applied Sciences. 7. 184-188(2013).

34. Sudhikumar, G. S., K. B. Prakash, and MV Seshagiri Rao. "Effect of aspect ratio of fibers on the strength characteristics of slurry infiltrated fibrous ferrocement." international journal of structural and civil engineering research" May (2014).

35. Ipek, Metin, et al. "Effect of pre-setting pressure applied flexure strength and fracture toughness of new SIFCON+ RPC composite during setting phase." Construction and Building Materials 79: 9096 (2015).

36. Sharma, Shashi Kant, Aniruddha D. Chopadekar, and Samarth Y. Bhatia. "Performance of SIFCON with Steel Slag." Kalpa Publications in Civil Engineering 1 198-208(2017).

37. Drdlová, Martina, and Vladan Prachař. "The Static And Dynamic Properties Of Slurry Infiltrated Fibre Concrete With Waste Steel Fibres From Tires." International Journal of Structural And Civil Engineering Research 7.1 (2018).

38. Ipek, Metin, and Mecbure Aksu. "The effect of different types of fiber on flexure strength and fracture toughness in SIFCON." Construction and Building Materials 214 :207218(2019).

39. Mohan, A., et al. "Investigation on ultra high strength slurry infiltrated multiscale fibre reinforced concrete." Materials Today: Proceedings 22: 904-911(2020).

40. Indharani D, et al. "strength properties of sifcon using of artificial fibers." International Journal of Advanced Research in Engineering and Technology (IJARET) Volume 10, Issue 4pp. 159-163, JulyAugust 2019.

41. Kim, Seungwon, Cheolwoo Park, and Yongjae Kim. "Effect of SIFRCCs with Varying Steel Fiber Volume Fractions on Flexural Behavior." Applied Sciences 10.6 :2072(2020).

42. Sippriya, J. Jeya, Danish Anwar, and Asif Alam. "DEVELOPMENT STRENG CONCRETE BY SIFCON U." International Journal of Civil Engineering 8.7 (2017).

43. Elavarasi, Sri \& K, Saravana \& A, Navatejareddy \& R, Sushmitha. Effect of Fibre Content on Mechanical Behavior of Slurry Infiltrated Fibrous Concrete. International Journal of Engineering \& Technology. 7. 260. 10.14419/ijet.v73.12.16037, (2018).

44. Kim, Seungwon, et al. "Tensile Behavior Characteristics of HighPerformance Slurry-Infiltrated Fiber-Reinforced Cementitious Composite with Respect to Fiber Volume Fraction." Materials 12.20 (2019).

45. Al-Abdalay, Nadia Moneem, Husein Ali Zeini, and Huda Zuhair Kubba. "Investigation of the Behavior of Slurry Infiltrated Fibrous Concrete."(2020)

46. Salih, S., Frayyeh, Q., \& Ali, M. Fresh and some mechanical properties of sifcon containing silica fume. In MATEC Web of Conferences (Vol. 162, p. 02003). EDP Sciences (2018).

47. Afroughsabet, V., \& Ozbakkaloglu, T. Mechanical and durability properties of high-strength concrete containing steel and polypropylene fibers. Construction and building materials, 94, 73$82(2015)$

48. Armagan, K., \& Canbaz, M. Effect of fiber type on freeze thaw durability of SIFCON International. Journal of Advances in Mechanical and Civil Engineering, 3(5), 56-59(2016).

49. Sherolkar and Jadhao, Durability assessment of slurry infiltrated fiber concrete by using various pozzolanic materials, The Indian concrete journal, April 2018, Vol.92, Issue 4, pp.56-61(2018). 
50. Elavarasi, D., \& Mohan, K. S. R. Effect of fly ash on strength and durability of slurry infiltrated fibrous concrete. Revista Romana de Material, 48(4), 529(2018).

51. Alrubaie, M. F., Salih, S. A., \& Abbas, W. A, Durability of Slurry Infiltrated Fiber Concrete to Corrosion in Chloride Environment: An Experimental Study, Part I. International Journal of Civil and Environmental Engineering, 13(8), 502-508. (2019).

52. Alrubaie, M. F., Salih, S. A., \& Abbas, W. A. The Effect of Acid Rain on Strength and Corrosion Performance of Slurry Infiltrated Fiber Concrete. Zanco Journal of Pure and Applied Sciences, 31(s3), 150-158 (2019).

53. Shelorkar, Ajay \& Jadhao, Pradip. Effects of Steel Slag on Durability Properties of Slurry Infiltrated Fibrous Concrete. 8. 143148. 10.35940/ijeat.D6501.088619 (2019).

54. Beglarigale, A., Yalçınkaya, Ç.Yiğiter, H., \& Yazıcı, H. Flexural performance of SIFCON composites subjected to high temperature. Construction and Building Materials, 104, 99-108 (2016).

55. Sherolkar and Jadhao, "Residual strength and micro structural identification of slurry infilterated fibrous concrete at elevated temperature", The Indian concrete journal, August 2019.

56. Abbas, A. S., \& Kadhum, M. M. Impact of Fire on Mechanical Properties of Slurry Infiltrated Fiber Concrete (SIFCON). Civil Engineering Journal, 6, 12-23 (2020).

57. Hashim, A. M., \& Kadhum, M. M. Compressive Strength and Elastic Modulus of Slurry Infiltrated Fiber Concrete (SIFCON) at High Temperature. Civil Engineering Journal, 6(2), 265-275 (2020).

58. Kim, S., Oli, T., \& Park, C. Effect of Exposure to High Temperature on the Mechanical Properties of SIFRCCs. Applied Sciences, 10(6), 2142 (2020).

59. Hameed, D. H., Alrubaie, M. F., Salih, S. A., Habeeb, G. M., \& Abbas, W. A. Slurry Infiltrated Fiber Concrete as Sustainable Solution for Defected Buildings. Engineering and Technology Journal, 37(1 Part (c) special) (2019).

60. Hameed, D. H., Salih, S. A., \& Habeeb, G. M. Precast epoxy fasten SIFCON layers as a retorting material for defected concrete. In AIP Conference Proceedings (Vol. 2213, No. 1, p. 020086). AIP Publishing LLC (2020, March).

61. Hameed, D. H., Salih, S. A., \& Habeeb, G. M. Upgrading of normal concrete service life by using SIFCON layers. In IOP Conference
Series: Materials Science and Engineering (Vol. 737, No. 1, p. 012045). IOP Publishing. (2020, February).

62. Abdollahi, B., Bakhshi, M., Mirzaee, Z., Shekarchi, M., \&Motavalli, M. SIFCON strengthening of concrete cylinders in comparison with conventional GFRP confinement method. Construction and Building Materials, 36, 765-778 (2012).

63. Helal, R. A., Al-Baghdadi, H. M., \& Al-Salim, N. H. A. Using Mortar Infiltrated Fiber Concrete as Repairing Materials for Flat Slabs. Civil Engineering Journal, 6(10), 1956-1973 (2020).

64. Misir, I. S., \& Kahraman, S. Strengthening of non-seismically detailed reinforced concrete beam-column joints using SIFCON blocks. Sadhana, 38(1), 69-88(2013).

65. Balaji, S., \& Thirugnanam, G. S. Cyclic Behavior of Exterior Beam-Column Joints Strengthened with Precast Slurry Infiltrated Fibrous Concrete Laminates. Journal of Engineering \& Technology, 4(1) (2014).

66. Balaji, S., \& Thirugnanam, G. S. Study on exterior RC beamcolumn joints upgrade with SIFCON in joint core under reversed cyclic loading. KSCE Journal of Civil Engineering, 21(1), 346-352 (2017).

67. Balaji, S., \& Thirugnanam, G. S. Behaviour of reinforced concrete beams with SIFCON at various locations in the beam. KSCE Journal of Civil Engineering, 22(1), 161-166 (2018).

68. Wu, Y. F., Jiang, J. F., \& Liu, K. Perforated SIFCON blocks-An extraordinarily ductile material ideal for use in compression yielding structural systems. Construction and Building Materials, 24(12), 2454-2465 (2010).

69. Farnam, Y., Moosavi, M., Shekarchi, M., Babanajad, S. K., \& Bagherzadeh, A. Behaviour of slurry infiltrated fibre concrete (SIFCON) under triaxial compression. Cement and concrete research, 40(11), 1571-1581(2010).

70. Tuyan, M., \& Yazıc1, H. Pull-out behavior of single steel fiber from SIFCON matrix. Construction and Building Materials, 35, 571-577 (2012).

71. Olutoge, F. A., Ofuyatan, O. M., Olowofoyeku, O. A., Bamigboye, G., \& Busari, A. A. Strength Properties of Slurry Infiltrated Fibrous Concrete (SIFCON) Produced with Discrete Bamboo and Steel Fibres. ARPN Journal of Engineering and Applied Sciences, 11(23), 13448-13453(2016). 